\title{
A Quantitative Study on the Translation Strategy of Material Culture-loaded Words in The Story of Stone by David Hawkes
}

\author{
QIAN Ya-Xu \\ Southwest Jiaotong University, Chengdu, China
}

\begin{abstract}
The culture-loaded word is a symbol of national culture, since national culture with distinctive features is directly or indirectly reflected in its vocabulary. This paper is driven both by qualitative research and by quantitative method through the comparison and analysis of translation strategies involved in the five types of material culture-loaded-words, namely, apparel, diet, equipment, architecture and medicine, in The Story of Stone by David Hawkes. With the final quantitative statistics of the proportion of each translation method, it aims to scrutinize either the broad spectrum or the specific characteristics of those translation strategies so as to provide a perspective for the study of cultural translations.
\end{abstract}

Keywords: material culture-loaded words, the multi-dimensional equivalence, the translation strategy, The Story of Stone by David Hawkes

\section{Introduction}

The Dream of Red Mansions, as the pinnacle of Chinese classical literature, embraced its first full-fledged English translation by David Hawkes in 1970s, i.e. The Story of Stone, which did give a fresh impetus to the spread of Chinese culture in the Western world. Lin Yiliang, a translator and red scientist who had a correspondence with Hawkes, said, The Story of Stone shows that David Hawkes and his co-translator John Minford are the finest stylist in the English literary translation (Lin, 2001, p. 63). Obviously, this translation is worthy of careful study because of the difficulty of cultural translations itself as well as its excellence. Five books by Lin (1976), Liu (2004), Feng (2006), Xiao (2009) and Hong Tao (2010), together with other articles scattered in the major newspapers and periodicals, have analyzed the advantages and disadvantages of Hawkes' translations, such as his translation features, mistranslations and missing translations, etc. However, those qualitative studies could only reflect some specific aspect related to The Story of Stone. Their selected examples are very random and have high repetition rate. With the quantitative research method, this paper is, therefore, intended to scrutinize each proportion of the material culture-loaded words translation methods in The Story of Stone, so as to further analyze either the broad spectrum or the specific characteristics of David Hawkes' cultural translation strategies.

QIAN Ya-xu, Lecturer of English Department in Foreign Languages School of Southwest Jiaotong University, Chengdu, China. 


\section{Research Methodology}

According to Eugene Nida's classification of cultural types, culture-loaded words can be divided into five categories: economic culture-loaded words, material culture-loaded words, social culture-loaded words, concept culture-loaded words, and language culture-loaded words. This paper will choose material culture-loaded words translated by David Hawkes in The Story of Stone as the research objective. They are further divided by Sun Xun, the editor of The Dream of Red Mansion Appreciation Dictionary into five categories: 107 words of costume, 91 words of food, 164 words of utensil, 74 words of buildings, 147 words of medicine, and 583 articles in total. In terms of Hawkes' cultural translation strategies, the paper finds that he mainly uses the foreignizing translation such as transliteration, literal translation, explanation and substitution as well as the domesticating translation such as addition, subtraction and combination methods in translating these material culture-loaded words. The final quantitative statistics about these translation strategies will be illustrated in Table 1. According to Nida's the multi-dimensional equivalence theory, this paper aims, finally, to make a qualitative analysis of the advantages and disadvantages of the Hawkes' translation in dealing with each type of material culture-loaded words.

Table 1

Quantitative Analysis for Parameter Table for Translation Methods of Material Culture-loaded Words in the Story of Stone

\begin{tabular}{|c|c|c|c|c|c|c|c|c|c|c|}
\hline & & $\begin{array}{l}\begin{array}{l}\text { Costume } \\
\text { words }\end{array} \\
\end{array}$ & \begin{tabular}{|l|}
$\begin{array}{l}\text { Food } \\
\text { words }\end{array}$ \\
\end{tabular} & $\begin{array}{l}\begin{array}{l}\text { Utensil } \\
\text { words }\end{array} \\
\end{array}$ & \begin{tabular}{|l|}
$\begin{array}{l}\text { Build-ing } \\
\text { words }\end{array}$ \\
\end{tabular} & $\begin{array}{l}\text { Medi-cin } \\
\text { e words }\end{array}$ & $\begin{array}{l}\text { Total } \\
\text { numbers }\end{array}$ & \multicolumn{2}{|c|}{ Percentage } & Ranking \\
\hline \multirow{4}{*}{$\begin{array}{l}\text { Foreignizing } \\
\text { translation } \\
\text { strategy }\end{array}$} & $\begin{array}{l}\text { Trans } \\
\text { literation } \\
\end{array}$ & 3 & 4 & 7 & 0 & 3 & 17 & $2.92 \%$ & \multirow{4}{*}{$38.59 \%$} & 5 \\
\hline & Literal translation & 36 & 41 & 56 & 20 & 55 & 208 & $35.68 \%$ & & 2 \\
\hline & Explanation & 8 & 2 & 10 & 2 & 2 & 24 & $4.12 \%$ & & 4 \\
\hline & Substitution & 49 & 19 & 67 & 34 & 55 & 224 & $38.42 \%$ & & 1 \\
\hline \multirow{3}{*}{\begin{tabular}{|l|} 
Domesticating \\
translation \\
strategy
\end{tabular}} & Addition & 0 & 1 & 5 & 1 & 3 & 10 & $1.72 \%$ & \multirow{3}{*}{$52.49 \%$} & 6 \\
\hline & Subtraction & 6 & 8 & 15 & 8 & 9 & 46 & $7.89 \%$ & & 3 \\
\hline & Combination & 0 & 0 & 0 & 0 & 2 & 2 & $0.34 \%$ & & 7 \\
\hline \multicolumn{2}{|l|}{ Mistranslation } & 3 & 12 & 3 & 2 & 11 & 31 & \multicolumn{2}{|l|}{$5.32 \%$} & \\
\hline \multicolumn{2}{|c|}{ Missing translation } & 2 & 4 & 1 & 7 & 7 & 21 & \multicolumn{2}{|l|}{$3.6 \%$} & \\
\hline \multicolumn{2}{|l|}{ Total numbers } & 107 & 91 & 164 & 74 & 147 & 583 & & & \\
\hline
\end{tabular}

\section{An Analysis on Hawkes' Cultural Translating Strategies With the Statistical Results}

Alienation and domestication are two common methods used in the translation: the alienation strategy is used to faithfully introduce the source language culture; the domestication strategy is applied to promote the acceptability of the text in the culture of the target language. It can be seen from Table 1 that the domestication method used by Hawks in dealing with the material culture-loaded words accounted for $52.49 \%$, which is higher than the alienation method (38.59\%) he used. According to the ranking of their usage frequency, the paper tries to analyze the detailed features of each translation strategy as follows:

\section{Substitution Strategies}

It is known to all that the words in the original version of the Story of Stone are extremely delicate. For example, when it comes to silk, there will be various Chinese expressions such as “缎纱绸绫、刻丝弹墨、妆 蟒绣堆” in terms of different original places, crafts and patterns. Because of these rich vocabulary, readers can 
enter the space of imagination to feel the ancient Chinese nobleman's luxury life and get an unusual aesthetic experience. However, due to the different historical sediments of China and English-speaking countries, cultures such as clothing, food, and architecture have their own characteristics. Therefore, in terms of language, there are many words that are semantically zero-equal or partially equivalent. The substitution method can be used as an effective compensation method to achieve different degrees of equivalence between original culture and target culture. Throughout the statistic results, Hawks' most frequently used translation method is the substitution, up to $38.42 \%$, with three kinds of cases, namely, completely successful, partially successful and failed substitution.

Completely successful substitution translation. The translation of “玫瑰卤子” eaten by Bad Yu into “the rose syrup” is a very successful substitution. “卤子” does not exist in Western culture, but there are syrups in the West. Although they are not the same thing, they are all viscous liquids. Because readers have the ability to associate, when they see syrup, they must form similar images in their minds. Similar examples are: “燕窝 粥” is translated by Hawks into “the bird's nest syrup”. Although its original meaning is a kind of porridge, it is actually a viscous liquid. Therefore, syrup is closer to the culture of the original text.

Partially successful substitution translation. Regarding some partially successful substitution strategies in Hawkes' translation, he always uses "upper words" in English to replace "lower words" in Chinese so as to preserve the most basic semantic transmission. For example, he translates various dressing expression such as “掩衿、补子、背心” into one word “jacket”. The benefits of this approach are obvious because the target reader can quickly understand their meanings, but compared with the reader of the source language, their aesthetic experiences can not be equal. The source readers will produce a lot of images about costumes in their brains with the richness of Chinese vocabulary, whether or not they understand these meanings. However, the translation vocabulary is single, and it is impossible to arouse the same rich associations of the reader. The similar examples goes as follows: “高几、炕桌、小几” are all translated into table; Cao Xueqin uses “茄豢” to show Mrs. Lian's clever tongue, and that is translated as “dried aubergine” by David Hawkes. It actually is a kind of dried eggplant or aubergine, and the translation version can realize the basic transfer of semantics, but there is a lack of stories. Such a compensatory feature is the basic pragmatic function of this substitution method.

Completely failed substitution translation. However, in some cases, it is not suitable for this alternative method. For example, Hawkes translates all kinds of Chinese alcohol into wine, which is not appropriate. Because Chinese alcohol and Western red wine are very different in terms of both their tastes and the production process. Perhaps this is like a method of domesticating translation, such as translating Buddhism in the Chinese original into Christianity in English version. However, if there are different degrees of equivalent vocabulary in the culture of the target language, it is unwise to choose vocabulary that is too different to replace the source word.

\section{Literal Translation Strategies}

In The Story of Stone, the foreignization-based literal translation method ranks the second after the substitution strategy, with a total appearance of 208 times, especially in translating the medical vocabulary (55 words) and the dietary vocabulary (41 words). The analysis is divided into the following three cases: 
- If the vocabularies in both cultures are same, they can be translated literally. For example, pigs, sheep, beef tongues, deer tendons, and duck porridge can be found both in English and in Chinese world, so Hawkes uses a large number of literal translations when translating such words. The reason is that, although there are differences in Chinese and Western diets, we all live together on the earth and have a similar physiological and physical basis. Therefore, the Chinese and Western cuisine have a lot in common in ingredients, so there is the same equivalent vocabulary in two cultures.

- With the frequent exchanges of modern society and culture, the number of foreign vocabulary has been increasing. Some of the vocabulary in Chinese culture has entered English vocabulary, such as "Yin", "Yang" and "Koutou”. It is the very case that the ancient tools for torturing people, i.e. “枷” can be translated directly as "cangue".

- However, it should be noted that if the cultural references are not the same and are not absorbed by the target language culture, it is not appropriate to use the literal translation method, which is also the third case. For example, in the chapter forty-one, “老君眉” is a kind of white tea produced in the Junshan area of Dongting Lake, Hunan. Hawkes literally translates it into Old Man's Eyebrows. Although it is said that this is a kind of tea, foreign readers who lack the background knowledge of Chinese tea culture, do not know anything about the color, smell, taste and shape of this tea. They are even confused about the name of this tea-What is on earth the relationship between tea and "old eyebrows"? Moreover, in the original text, Grandmother Jia said: “I don’t eat Liu'an tea.” Adamantina said: “I Know it. This is the Old Man’s Eyebrow.” Here, they seemingly talk about the name of the tea, but the underlying message refers to the type of the tea. Because Liu'an tea is green tea; the Old Man's Eyebrow is white tea. Grandmother Jia actually said that she did not drink green tea, and Adamantina indicated that she was holding white tea. Therefore, the literal translation without any explanation in this case easily leads the western reader to confusion.

\section{Subtraction Strategies}

The subtraction method ranking the third place also includes three cases in terms of their translation effects:

Completely successful subtraction translation. It is very successful to translate “暖香坞” that appeared many times in the original text into The Spring in Winter. Because it is the title of a house which is usually used by the ancient Chinese to hang above the door of the house, the information carried by these three words should not be their literal meaning, but a kind of taste or mood. In the translation, the last word “坞” that means dock is omitted. However, only by such an subtraction did bring about a little more artistic conception. The Spring in Winter is actually giving people a sense of beauty, thus achieving the aesthetic level of information transmission.

Partially successful subtraction translation. When dealing with many culture-loaded words, Hawkes adopted this simplified domestication method to achieve basic semantic equivalence in order to facilitate the understanding of Western readers. For example, in the chapter fifty-two, when Mr. Bao goes out in a snowy day, his servant girl lets him put a piece of pickled ginger to his mouth for warmth. “法制紫姜” that is the Chinese original expression was simplified as a piece of ginger in the translation, which saved the basic meaning by lacking of its processing way. However, even if you know that this ginger is honey-flavored or 
pickled, it is not very important, at least not affecting the understanding of the core semantics. However, if the term is not further explained, it is difficult for any Western reader who is not familiar with Chinese health culture to establish any connection between "eating ginger" and "getting warm". In the above case, the subtraction method at least achieves partial equivalence in terms of the core or basic meaning .

Completely failed subtraction translation. In the following example, this kind of subtraction translation is completely unsatisfactory. In the twenty-eighth chapter, “为君的药” was simply translated as "sovereign remedies" whose meaning is a miracle medicine or panacea, which is far from the original intention. In the culture of Chinese medicine, according to the patient's condition, the medicinal properties and doses of the various drugs used, the medicines are divided into four types: Jun (君), Chen (臣), Zuo (佐), and Shi (使). One of the main drugs is called “为君 (Jun) 的药”. Therefore, it can be seen that the original meaning and the translation version are totally different.

\section{Explanation Strategies}

In the statistical sample, Hawkes used a total of 24 explanation methods, accounting for $4.12 \%$, ranking fourth. This method is suitable for not finding the English corresponding words, and can not replace the Chinese source words with synonyms. For example, there is a name of food in the chapter of forty-one called “小面果” in Chinese, but such one word was translated into a group of words for explanation, namely, fried confection consisted of a wide variety of little pastry-shapes deep-fried. It is actually a kind of traditional food in Beijing. They are not only different in style, but also have different tastes. Obviously, this unique Chinese food cannot find any equivalent in English, so Hawkes tries to explain it for seeking a better understanding among western readers.

\section{Transliteration Strategies}

Hawkes also used the transliteration method when dealing with the "zero equivalent" in the Chinese and British cultures. In the sample statistics, there were 17 times of transliteration strategies, accounting for 2.92\% of the total, ranking fifth. For example, “文王鼎” in Mrs. Jia’s room was translated into a small, square, four-legged ding. Some scholars believe that Hawkes does not further explain what "Ding" is, which can only make the readers feel confused (ZHANG, 2000, p. 58). However, the paper holds the view that this pure transliteration without explanation is acceptable in this case. Although, at first glance, "ding" is a symbol that has no meaning for English readers who lack the background of Chinese culture. However, as far as their understanding is concerned, it is not difficult to guess that it is a four-legged, square small object by means of the above description. On the reader's acceptance level, Eugene Nida of the United States pointed out that the translator's most serious mistake is to underestimate the ability of adult readers in other cultures (Nida, 1964, p. 143).

However, in the following example, it is not satisfactory to totally use this translation strategy. When Cao Xueqin described the furnishings in Tanchun's room, he mentioned a flower-vase, i.e. “汝窑花囊” that was translated as flower-vase of Ru ware by Hawkes. In this case of transliteration without explanation, it is probably hard to understand the important position of "Ru" in Chinese porcelain culture, i.e., one of the five famous official kiln in the Song Dynasty including Ru (汝), Guan (官), Jun (钧), Ge (哥), Ding (定), especially for those English readers who lack the knowledge of Chinese porcelain; when it comes to pronunciation, 
Western readers can hardly imagine the color and the glaze of the porcelain produced by the Ru kiln. Due to the lack of these cultural backgrounds, it is bound to affect their understanding of both Chinese nobleman's luxury life and the nature of the Tanchun. Therefore, the author believes that the transliteration involving important heterogeneous cultural information needs to be further explained through adding some notes.

\section{Addition Strategies}

There are a total of 10 addition translations in the listed statistics, accounting for $1.72 \%$. Hong Tao pointed out that the Western reader are unfamiliar to the books, poems and operas often mentioned in the original text, because they do not have the same literature knowledge as the Chinese readers do, especially the readers of the Qing Dynasty at the same time as Cao Xueqin. Therefore, Hawkes amplified the text in the translation to help the target readers understand the Chinese culture (Hong, 2010, p. 140). For example, in the description the layout of Qin Keqing’s room, Cao Xueqin mentioned “寿昌公主于含章殿下卧的榻” that was translated as "the priceless bed on which Princess Shou-yang was sleeping out of doors under the eaves of The Han-zhang Palace when the plum-flower lighted on her forehead and set a new fashion for coloured patches”. Literally, it should be merely translated into "the bed on which Princess Shou-yang was sleeping out of doors under the eaves of The Han-zhang Palace”, but the translator amplified the text by tell the full story of Shouchang princess lying under the sacred temple. Plum blossoms fell on the princess's forehead, and the five-flower shape had lingered there for three days. Today, the plum makeup is also a fashion. As a result, Hawkes successfully passed on Chinese history and culture. Compared with the method of explanation with notes, it has the same effect. In addition, the original "Shouchang" is the mistake of "Shouyang", Hawkes' translation has been revised by himself (Hong, 2010, p. 142).

David Hawkes also used this method when translating vocabulary involving Chinese medicine culture. For example, when describing Qin Keqing seeing a Chinese doctor, Mr. Zhang, Cao Xueqin wrote that Mr. Zhang regulated his own breathing, but Hawkes amplified the text by the translation as follows: He regulated his own breathing in order to be able to count the rate. Although the conceptual meaning of the original text does not include the purpose of "counting the rate of the patient's pulse", the amplified translation is implicit in the language for readers who do not understand Chinese medicine. This is also the case when Hawkes translated the "ginseng suop" that Jia Rui had to drink after being teased by Mrs. Lian into "a pure decoration of ginseng without admixture of other ingredients".

\section{Combination Strategies}

When Hawkes deals with the material culture-loaded words in The Story of Stone, some translations do not belong to any single method, but have to use two or more combination strategies. For example, with literal translation plus free translation, “上用银丝挂面” that is a kind of noodle was translated as “the finest silver thread vermicelli” by Hawkes; or with substitution plus addition translation strategies, “寿桃” was translated as "peach-shaped birthday cakes”. In fact, any kind of translation method cannot adapt to all situations in dealing with the culture-loaded words; thus this combination method could be taken as a good means of cultural compensation. 


\section{Mistranslation \& Missing Translation}

\section{Mistranslation}

It can be seen from the statistics that there are a small number of mistranslations (31 in total, accounting for 5.32\%) in Hawkes' translation of culture-loaded words in The Story of Stone. Although he is a famous sinologist, his understanding of Chinese culture still has a lot of limitations, which may cause such mistranslation. For instance, in the WON-DONE SONG (《好了歌》), “因嫌纱帽小” is misinterpreted as “the judge whose hat is too small for his head”. Actually, “乌纱帽” that is a black hat is simply understood by him as a hat, but its rhetorical meaning is "the official position", so that foreigners can not know the underlying meaning, while the Chinese would probably feel ridiculous.

From the statistical data, among the above five categories, namely, the words of costume, food, utensil, buildings and medicine, the proportion of mistranslation in the medicine translation is the highest. The paper tries to analyze the reasons for the following two points:

- The name of Chinese medicine is very professional, so it is necessary to understand the whole Chinese medical culture to achieve the correctness of delivering such kind of message. For example, Hawkes wrongly translated “头胎紫河车” which actually is the placenta into “the caul of a first-born child”, because he may not know that in the Chinese medicine, “河车” is the placenta of the baby that has the effect of tonifying Qi and blood. In the old days, it was considered to have three colors of green, red and purple. The purple one is excellent, so “头胎紫河车” that literally is the first-born’s purple placenta means that this medicine mentioned by Mr. Bao was the most potent, which could also show his knowledge and position. However, if it was translated into caul, i.e., the membrane on the baby's head, such a translation could bear no Chinese medical culture at all.

- When Hawkes translated some names of the Chinese medicine containing so much abstract cultural connotation, he could creatively adopt its basic semantics by losing its form without bounding by its literal meaning, which was desirable. However, due to cultural differences and professional knowledge, he did not fully understand the effects behind some drug names, which led to mistranslation. For example, in the fortieth chapter, “紫金锭”, a medicine for detoxification, sore alleviation, typhoid plague, diarrhea and dysentery, and pediatric paralysis, was translated into "the Old Gold Anti-Fever Pastilles”, becoming a fever-reducing drug. Readers may find that the drug is not symptomatic; furthermore, careful readers would mistake the author in terms of his loose logic.

Mistranslations in other types of material culture-loaded words are mostly due to the translator's lacking enough knowledge of Chinese culture. Take “酱萝卜炸儿” in the sixth chapter for example. Hawkes translated it as “fried pickled turnips in gluten batter”, but “炸儿” has nothing to do with any gluten batter, and it actually is a northern dialect to mean the degree of crispy pickled radish (Sun, 2005, p. 588).

\section{Missing Translation}

Regarding the missing translation (a total of 21, accounting for 3.60\%), there is no significant impact on the material culture transmission because the missing part is just unimportant information. In the chapter three, Cao Xueqin described what Mrs. Jia’s eastern room look like in Dai-yu's eyes when she first came to the house of Jia. Hawkes' translation goes like that “a large kang underneath the window, covered with a scarlet Kashmir rug. In 
the middle of the kang was a dark-red bolster with a pattern of medallions in the form of tiny dragons, and a long russet-green seating strip in the same pattern” (Hawkes, 1973, p. 96). In the original Chinese text, there are four items - the shackles, the backrests, the pillows, and the big shackles, but only three were left in the translation, namely, rug, bolster, and sewing strips without the pillow. However, from the perspective of the overall effect, Hawkes grasped the core of the translation by showing readers the family Jia's luxury life through those ornaments, patterns and colors. Though one item was missing, the language of translation was smooth, and it did not affect the English readers' access to semantic and visual information.

\section{Conclusion}

Throughout the long history of human development, the cultures of all ethnic groups in the world have commonalities and individuality, and the culture-loaded words are aimed at cultural individuality. The diversity and complexity of culture itself determine the flexibility of the translation strategy in dealing with culture-loaded words. In terms of the material culture-loaded words in The Story of Stone, David Hawkes used the domestication method accounting for $52.49 \%$ and the alienation strategy (38.59\%). The former includes transliteration, literal translation, explanation and substitution methods, and the latter can be further divided into addition, subtraction and combination translation strategies. The reason, on the one hand, is that the material culture-loaded words also contain some common foundations since we all live on the same planet, which provides the possibility of literal translation; on the other hand, it also reflects the heterogeneity of the two cultures of Chinese and English that need various means of cultural compensation to achieve the basic meaning or function equivalence. In this case, the combination method, though Hawkes seldom used it, could be the most effective way by adopting more than two alternatives to achieve a three-dimensional equivalence between the source language and the target language. It can also realize the combination of domestication and foreignization in the cultural translation by maximizing the heterogeneous cultural information of the source language within the acceptable range of the target language reader.

There are still many shortcomings in this study, since the process of categorizing translation methods before generating statistical data still has great subjectivity, though the operability of quantitative research in the humanities field and its intuitive advantages are seen. In fact, it is hard to put some translation into any classification due to the overlapping among those strategies. In order to facilitate the final statistics, the main translation methods are finally chosen. However, in general, quantitative study method has great practical significance in the translation research.

\section{References}

Feng, Q. H. (2006). Research on the translation art of A Dream of Red Mansions. Shanghai: Shanghai Foreign Language Education Press.

Hawkes, D. (1973, 1977, 1980). The story of stone. Harmondsworth: Penguin book Ltd.

Hong, T. (2010). On the intercultural transfer and academic knowledge barriers from the translation of A Dream of Red Mansions. Beijing: National Library of China Publishing House.

Lin, Y. L. (1976). A detailed review of the new English translation of A Dream of Red Mansions. Taibei: United Publishing Company.

Lin, Y. L. (2001). Wen si lu. Liaoning: Liaoning Education Publishing House. 
Liu, S. C. (2004). A review on translation and research papers of A Dream of Red Mansions. Tianjin: Nankai University Press. Nida, E. A. (1964). Toward a science of translating. Leiden: E. J. Brill.

Sun, M. (2005). Appreciation dictionary of A Dream of Red Mansions. Shanghai: Chinese Language Dictionary Publishing Agency. Xiao, J. Y. (2009). Study of English translation of conceptual metaphor in A Dream of Red Mansions. Beijing: China Social Sciences Press.

Zhang, H. Y. (2000). Comment on the translation of culture-loaded words in A Dream of Red Mansions.Journal of Anhui University. 